\title{
Dural tear with multiple nerve root entrapment simultaneously after unstable spine injury: Intraoperative finding
}

\section{Farid Yudoyono ${ }^{1,2}$ \\ Arief Pebrianto ${ }^{2}$}

'Neurospine and Pain Center, Santosa Hospital Bandung Kopo, Bandung, Jawa Barat, Indonesia ${ }^{2}$ Department of Neurosurgery, Hasan Sadikin Hospital, Bandung, Jawa Barat, Indonesia
Cite this article:

Yudoyono F, Pebrianto A. Dural tear with multiple nerve root entrapment simultaneously after unstable spine injury: Intraoperative finding. Neurologico Spinale Medico Chirurgico. 202I.4(I):7-I0. DOI: 10.36444/nsmc.v4i I.I34

Corresponding author:

Farid Yudoyono

Neurospine and Pain Center, Santosa Hospital Bandung Kopo, Bandung, Jawa Barat, Indonesia faridspine@gmail.com

\begin{abstract}
Spinal cord injuries (SCIs) caused by trauma that frequently occur are dural tears and cerebrospinal fluid (CSF) leaks. They are not always detected with neuroimaging. Hence, the authors reported two cases of the dural tear with multiple nerve root entrapment after spine injury and described how managed. This case report was about two patients who had unstable spinal fractures. All patients have an asymmetrical neurological deficit. The following magnetic resonance imaging features have analyzed the presence of CSF leakage, epidural haematoma, and spine fractures. Both cases revealed intraoperative finding dural tear with multiple nerve root entrapment. We performed decompression with spinal fixation with a posterior approach, and then the patients were sent home without complication. During the follow-up period, none of the patients developed complications. The severe neurological deficit, fracture of laminar, and ligamentum flavum disruption on the MRI in patients were predictable factors in our cases.
\end{abstract}

Keywords: Dural tear, Traumatic spinal cord injury, Nerve root entrapment

\section{Introduction}

Spine injury is an important global health problem. Spinal cord injury causes disability, decreases the patient's quality of life, and also burdens the health system itself. The prevalence of spinal cord injury cases has increased globally from 1990 to 2016. The increase is largely related to the increasing number of traffic accidents and falls. The incidence in Southeast Asia reaches 5-9 cases per 100,000 population. In America, it is estimated that there are 17,000 cases per year, with the highest number of patients is male, $80 \%$, and the average age is 42 years. ${ }^{1,2}$ As many as $70 \%$ of spinal cord injury patients experience multiple injuries, which cause high rates of complications both in the long term and short term. ${ }^{3}$

Spine injuries often cause damage to the dura mater. ${ }^{3,4}$ dura mater tears are reported in 18$36 \%$ of cases of spinal cord injury. ${ }^{4}$ The most common location for damage to the dura mater is in the thoracic spine, with an incidence of 9-36\%. The high-energy trauma mechanism causes damage to the spinal canal so that it tore the dura mater. The cause can be burst injury, flexion-distraction trauma, and fracture-dislocation trauma to the spine. ${ }^{3}$ Tear in the dura itself most often occur due to burst fractures in the lumbar with vertical fractures in the lamina. ${ }^{4}$ 
Cerebrospinal fluid is a clear fluid produced mainly by the choroid plexus functions as a cushion or protector of the central nervous system from trauma and to nourish the central nervous system and regulate metabolic homeostasis of the central nervous system and others. ${ }^{5}$ When there is a defect in the dura mater, it can cause cerebrospinal fluid leakage. Other complications that can occur due to leakage of cerebrospinal fluid are the formation of pseudomeningocele, dura-cutaneous fistula, meningitis, arachnoiditis, epidural abscess, and subdural hematoma. ${ }^{3,6}$

Usually, a dural tear can be predicted preoperatively using magnetic resonance imaging (MRI). Cerebrospinal fluid leakage must be identified and managed appropriately to reduce the patient's morbidity. ${ }^{3,4,6}$

\section{Case report}

\section{Case I}

A 19-year-old male came with weakness on both of his legs after getting hit by a motorcycle when he crossed the road. In the emergency department, the Glasgow score was 15, systolic and diastolic blood pressures were 110/53 $\mathrm{mmHg}$, and heart rate was 110 bpm. The initial examination showed bilateral leg weakness grade 1/5 on the right and grade $3 / 5$ on the left side with sensory loss below the knee. Lower limbs reflexes were absent. There was no Babinski sign. There were perineal anesthesia and loss of the anal sphincter tone. Thoracic and pelvic X-rays were normal. A computed tomography (CT) scanning showed L4 vertebral burst fracture (Figure 1A). During surgery, we found a dural tear and multiple nerve root entrapment on the right side.

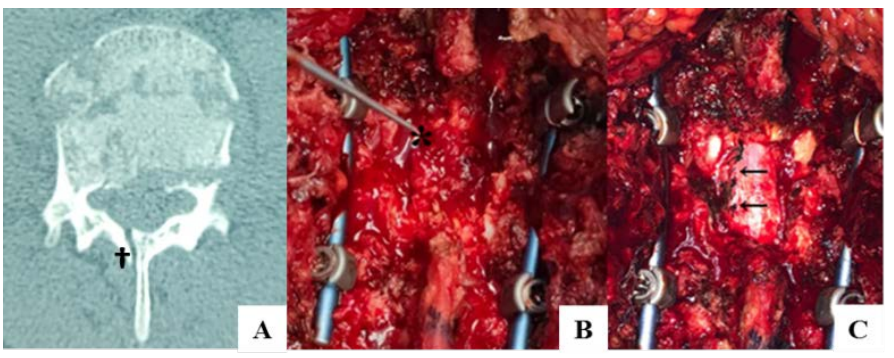

Figure 1. Plain lumbar spine $X$-ray in $A P$ and lateral view showing the fractured Figure 1. A) CT scan show lamina fracture. B) Multiple nerve root entrapment (asterisk). C) After reposition of nerve and primary suture of duramater (black arrows)

We performed decompression, removed huge epidural hematome, repositioned back nerve root into the thecal sac and applied double layered duroplasty, the defect with a synthetic dural patch into subdural space, after suturing DuraGen same size placed on outer duramater so dural tear fully covered (e.g., DuraGen, Integra Life Sciences Corp., USA) and fibrin glue sprayed around the margin of dural tear and performed spinal fixation (Figure $1 \mathrm{~B}$ and $1 \mathrm{C}$ ). The patient's neurological deficit slowly improved, and the pain disappeared with medication during the outpatient department visit.

\section{Case 2}

A 45-year-old male came to the Neurosurgery Emergency Department after falling from 10 meters in height. The patient complained of motor and sensory disturbance. On admission, he was conscious, Glasgow score was 15, systolic and diastolic blood pressures were 100/60 mmHg, and heart rate was 80 bpm. Physical examination revealed a swelling of the posterior neck. The initial examination showed all extremity muscle weakness grade $2 / 5$ on the right and grade 1/5 on the left side. An absence of sensitivity starts from C4 below. Deep tendon reflexes could not be obtained, Hoffman sign and Babinski sign was negative bilaterally. There were perineal anesthesia and loss of the anal sphincter tone. MRI showed cord contusion and hyperintense shadow from intracanal to outside on the same level (Figure 2A). A CT-scanning showed C5 vertebral burst fracture, spinous process fracture, and lamina fracture (Figure 2B and 2C). $\mathrm{He}$ was subsequently taken to the operating room. During surgery, we found a dural tear on the left side with nerve root entrapment and reposition back into thecal sac and primary suture and applied the defect with a synthetic dural (e.g., DuraGen, Integra Life Sciences Corp., USA) fibrin glue sprayed around the margin of dural tear and for posterior cervical instrumentation and fusion from C3 to C6. The patient neurological deficit slowly improved after surgery, and pain from his neck disappeared with medication during outpatient department visit.

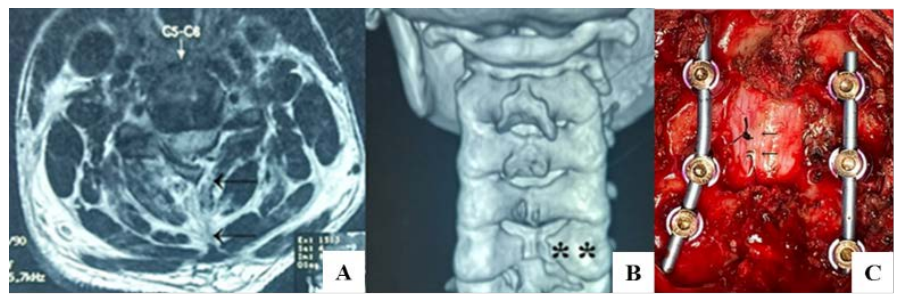

Figure 2. A) MRI T2WI show hyperintense shadow from intracanal (black arrows). B) 3D CT Scan show lamina and spinous process fracture (double asterisk). C) After reposition of nerve and primary suture of duramater (black arrows) 


\section{Discussion}

Spine injuries are often accompanied by dural tears and cerebrospinal fluid leakage. Dural tears in spine injuries are a result of the traumatic mechanism and laceration of the thecal sac. ${ }^{7-9}$ Incidence of traumatic dural tears were $18-36 \%{ }^{3}$ This injury usually unpredictable with neuroimaging such as MRI but revealed intraoperatively. Incomplete cervical cord injury is the most common clinical condition that constitutes $70 \%$ of all traumatic spinal cord injuries. ${ }^{4}$

In a previous study, dural tears with cerebrospinal fluid leakage after cervical bone trauma was higher than degenerative cervical disease and as often as hardening of posterior longitudinal ligaments. Smorgick et al., prospectively studied 523 patients underwent lumbar and thoracolumbar spine surgery revealed that dural tear happened from adhesion and scarring over the duramater are reason for many tears cases. ${ }^{10}$ Although age, sex, the height of injury, location of the laminar fracture, and the absence of a posterior fat pad signal is not related to dura tears, neurological deficits are predictors of dura tears. ${ }^{11}$ Worse American spinal injury scale and disruption of the ligamentum flavum seen on early MRI are also factors associated with significant CSF leakage. ${ }^{12}$ Therefore, it is likely that there will be intraoperative cerebrospinal fluid leakage in patients who present with poor neurological status and simultaneously show disruption of the ligamentum flavum on MRI post cervical bone trauma. In addition to signs and symptoms of cerebrospinal fluid leakage, disrupted neurological status prior to operative management, especially accompanied by findings of burst fractures and laminar fractures radiologically, are significant predictors of dura tears. ${ }^{11}$ The severity of neurological deficit and within 24 hours are important factors to decided the urgency of spine surgery. ${ }^{13,14}$

MRI with enhancement can find dura or subarachnoid cavity connections, the presence of pseudomeningocele. In one study, CTmyelography using intrathecal metrizamide to have been successfully used to find dura tears by observing the presence of contrast material coming out of the subarachnoid cavity. In addition, radioisotope cysternography is also useful for detecting sites of cerebrospinal fluid leakage. In addition to diagnosing dura tears, the above radiological method can also be used to diagnose cerebrospinal fluid fistulas. ${ }^{9}$ In a study analyzing MRI of patients with spinal burst fractures, MRI findings in the form of lamina fractures more than 1 degree, interpedicular distance $>28 \mathrm{~mm}$, central canal ratio $<0.46$, and acute angle of the retropulse segment $<135$ degrees can be used as the threshold for predicting dura tears. ${ }^{13,15}$
Cerebrospinal fluid leakage is usually visualized directly intraoperatively as a clear fluid leak. Extensive epidural bleeding or compression of the thecal sac are the indirect signs of dural tears. Dural tears may also not be detected until the postoperative period. Clear fluid or serousanguinus indicating dural tear and fistulas that formed, usually in the period of 1-7 days postoperative. Fluctuating mass can indicate the presence of pseudomeningocele. ${ }^{7}$

The author performed double layer duroplasty mean intradural and epidural patch to avoid CSF leakage after surgery and we used DuraGen for spinal dural tear management because it can be approximated tightly with the defects of any shape and size and additional sutures are not required. ${ }^{16,17}$ Our cases are unique because of dural tears associated with unilateral multiple nerve root entrapment simultaneously and asymmetrical neurological deficits. We believe this to be multifactorial. We assumed that the significantly increased force from a direct flexion-extension mechanism of injury and increase intraabdominal pressure followed by disruption of the posterior spinal structure caused a substantial pressure gradient across the dura. Therefore, following laceration, the pressure gradient forced some CSF that allows multiple nerve roots entrapped. Disturbance of axonal venous flow following nerves root entrapment could damage the myelin sheath resulting in edema and nerve root dysfunction. ${ }^{18,19}$

\section{Conclusion}

Traumatic dural tear with multiple nerve root entrapment can occur simultaneously after spinal injury. Poor initial neurological status, burst type fracture and disruption of posterior structure such as ligamentum flavum and lamina fractures on the patient's neuroimaging are predictors in our cases.

\section{Acknowledgment}

There is no potential conflict of interest relevant to this article reported. No specific grant was provided for this article. All authors took part in the design of the study, literature review, and writing of the manuscript.

\section{References}

1. GBD 2016 Traumatic Brain Injury and Spinal Cord Injury Collaborators. Global, regional, and national burden of traumatic brain injury and spinal cord injury, 1990-2016: a systematic analysis for the 
Global Burden of Disease Study 2016. Lancet Neurol. 2019;18(1):5687. DOI: 10.1016/S1474-4422(18)30415-0

2. National Spinal Cord Injury Statistical Center (NSCISC). Spinal cord injury (SCI) 2016 facts and figures at a glance. J Spinal Cord Med. 2016;39(4):493-494. DOI: 10.1080/10790268.2016.1210925

3. Stricsek G, Ghobrial G, Wilson J, et al. Complications in the management of patients with spine trauma. Neurosurg Clin $N$ Am. 2017;28(1):147-55. DOI: 10.1016/j.nec.2016.08.007

4. Luszczyk MJ, Blaisdell GY, Wiater BP, et al. Traumatic dural tears: what do we know and are they a problem? Spine J. 2014;14(1):49-56. DOI: 10.1016/j.spinee.2013.03.049

5. Tumani H, Huss A, Bachhuber F. The cerebrospinal fluid and barriers - anatomic and physiologic considerations. Handb Clin Neurol. 2017;146:21-32. DOI: 10.1016/B978-0-12-804279-3.00002-2

6. Chan SM, Chodakiewitz YG, Maya MM, et al. Intracranial hypotension and cerebrospinal fluid leak. Neuroimaging Clin $N$ Am. 2019;29(2):213-226. DOI: 10.1016/j.nic.2019.01.002

7. Campbell PG, Hanna A, Harrop JS. Spinal dural injuries. In Herkowitz HN, Garfin SR, Elsmont FJ, editos. Rothman-Simeone The Spine. $6^{\text {th }}$ ed. Philadelphia: Elsevier Saunders, 2011; 2: 1720-1727.

8. Rothman RH, Herkowitz HN, Simeone FA. Rothman-Simeone and Herkowitz's, the spine. $7^{\text {th }}$ ed. Philadelphia: Elsevier Saunders, 2018; 2: 1739-1746.

9. Epstein NE. A review article on the diagnosis and treatment of cerebrospinal fluid fistulas and dural tears occurring during spinal surgery. Surg Neurol Int. 2013;4(Suppl 5):S301-S3117. DOI: 10.4103/2152-7806.111427

10. Smorgick Y, Baker KC, Herkowitz H, et al. Predisposing factors for dural tear in patients undergoing lumbar spine surgery. $J$ Neurosurg Spine. 2015;22(5):483-486. DOI: 10.3171/2015.1.SPINE13864
11. Park JK, Park JW, Cho DC, et al. Predictable factors for dural tears in lumbar burst fractures with vertical laminar fractures. J Korean Neurosurg Soc. 2011;50(1):11-16. DOI: 10.3340/jkns.2011.50.1.11

12. Lee SE, Chung CK, Jahng TA, et al. Dural tear and resultant cerebrospinal fluid leaks after cervical spinal trauma. Eur spine $J$. 2014;23(8):1772-1776. DOI: 10.1007/s00586^014-3332-9

13. Rath N, Balain B. Spinal cord injury-The role of surgical treatment for neurological improvement. Journal of Clinical Orthopaedics and Trauma. 2017;8:99-102. DOI: 10.1016/j.jcot.2017.06.016

14. Ter Wengel PV, Feller RE, Stadhouder A, et al. Timing of surgery in traumatic spinal cord injury: A national, multidisciplinary survey. European Spine Journal. 2018;27:1831-1838. DOI: 10.1007/s00586018-5551-y

15. Lee DH, Kim KT, Park JI, et al. Repair of inaccessible ventral dural defect in thoracic spine: Double Layered Duraplasty. Korean J Spine. 2016;13(2):87-90. DOI: 10.14245/kjs.2016.13.2.87

16. Papavero L, Engler N, Kothe R. Incidental durotomy in spine surgery: First aid in ten steps. Eur Spine J. 2015;24:2077-2084. DOI: 10.1007/s00586-015-3837-x

17. Lee IS, Kim HJ, Lee JS, et al. Dural Tears in spinal burst fractures: predictable mr imaging findings. Am J Neuroradiol. 2009;30(1):142146. DOI: 10.3174/ajnr.A1273

18. Joseph Y. Multiple nerve root injuries after incidental durotomy: case report with anatomical correlation and review of literature. J Spine Neurosurg. 2018;7(2):1-5. DOI: 10.4172/2325-9701.1000296

19. Chang MY, Chan JY, Huang CT, et al. Cauda equina incarceration secondary to dural tears after lumbar microsurgical discectomy. Formosan J Surg. 2012;45:37-40. DOI: 10.1016/j.fjs.2011.12.001 